\title{
Research on Energy Response Characteristics of Rock under Harmonic Vibro-Impacting Drilling
}

\author{
Siqi $\mathrm{Li}^{1} \cdot$ Lipeng Yan ${ }^{2} \cdot$ Wei Li $^{1} \cdot$ Huan Zhao ${ }^{1} \cdot$ Xin Ling $^{1}$
}

Received: 7 December 2017 / Accepted: 10 April 2018 / Published online: 19 August 2019

(c) The Author(s) 2019

\begin{abstract}
Purpose There are still a number of challenges to be addressed for the harmonic vibro-impacting drilling technology to become the norm in the industry. The change mechanism of energy response of rock under harmonic vibro-impacting is one of the problems that needs to be solved, which is also an indispensable part of the rock-breaking mechanism of the technology. Thus, this study focuses on the modelling of energy response of rock under harmonic vibro-impacting.

Methods Modelling of energy response of rock with and without damping under harmonic vibro-impacting is undertaken and the corresponding equations of energy dissipation are presented in this study. Subsequently, the results of numerical calculation are given and the effects of natural frequency of rock, impacting frequency, impacting force and other parameters of energy response of rock are analyzed. Finally, a practical case is given to demonstrate the rock-breaking effect under harmonic vibro-impacting drilling.

Results The results show that energy response of rock with damping decays regularly over time in the harmonic form under harmonic vibro-impacting. Also, it increases with the increase of natural frequency and mass of rock, impacting frequency and force, and is not affected by the stiffness of the rock. In addition, the penetration rate in practice has been greatly improved under harmonic vibro-impacting.

Conclusions Based on the analysis undertaken, the variation mechanism of energy response of rock under harmonic vibroimpacting was found and the rock-breaking effect of the technology was verified. The study on the modelling of energy response of rock under harmonic vibro-impacting can provide a theoretical basis for applying harmonic vibro-impacting drilling technology.
\end{abstract}

Keywords Harmonic vibro-impacting $\cdot$ Energy response $\cdot$ Energy dissipation $\cdot$ Numerical calculation $\cdot$ Practical case

\section{List of Symbols}

$L$ Lagrange function

$q \quad$ Generalized coordinates, $\mathrm{m}$

$\dot{q} \quad$ Generalized velocity $(\mathrm{m} / \mathrm{s})$

$p \quad$ Generalized momentum $(\mathrm{kg} \mathrm{m} / \mathrm{s})$

$t \quad$ Time (s)

$H$ Hamiltonian function

$\omega$ Ideal natural frequency of rock ( $\mathrm{rad} / \mathrm{s})$

$\omega_{1}$ Actual natural frequency of rock $(\mathrm{rad} / \mathrm{s})$

$\omega_{i} \quad$ Impacting frequency $(\mathrm{rad} / \mathrm{s})$

Wei Li

tianxinxiaozhu647@163.com

Siqi Li

our.126@126.com

1 Department of Petroleum Engineering, Northeast Petroleum University, Daqing 163318, Heilongjiang, China

2 Sinopec Research Institute of Petroleum Engineering, Beijing 100101, China
$T \quad$ Kinetic energy (J)

$U_{1}$ Potential energy ( $\left.\mathrm{J}\right)$

$U_{2}$ External potential energy (J)

$x \quad$ Vibration displacement of rock $(\mathrm{m})$

$\dot{x} \quad$ Vibration velocity of rock $(\mathrm{m} / \mathrm{s})$

$\ddot{x} \quad$ Vibration acceleration of rock $\left(\mathrm{m} / \mathrm{s}^{2}\right)$

$k \quad$ Stiffness of rock $(\mathrm{N} / \mathrm{m})$

$m$ Mass of rock $(\mathrm{kg})$

$c \quad$ Damping coefficient of rock $(\mathrm{N} \mathrm{s} / \mathrm{m})$

$f \quad$ Amplitude of impacting force $(\mathrm{N})$

$F \quad$ Impacting force (N)

\section{Introduction}

As conventional oil and gas resources are drying up, deep and unconventional oil and gas resources have become an important strategic energy. However, the current techniques utilizing impacting energy to drill rock formations still 
cannot meet the demand of drilling at ever-increasing well depth. Slow penetration rate, drilling tool failure and other problems have always been the major troubles in drilling operation [1-3]. As a result, many efficient techniques for rock breaking are proposed to enhance the penetration rate [4-7].

Harmonic vibro-impacting drilling technology is one of the efficient rock-breaking technologies. The basic idea of the technology is that the bit, while rotating, applies a harmonic vibro-impacting force with an adjustable high frequency to the rock so as to make the rock drilled. In the harmonic vibro-impacting drilling, if the impacting frequency is the same as the natural frequency of rock, rock will be resonant, which is called resonance enhanced drilling (RED).

Since harmonic vibro-impacting drilling technology was proposed, many researchers have made great efforts in this field [8-11]. Li et al. [12]. analyzed the rock-breaking mechanism of drill tool under harmonic vibro-impacting both theoretically and experimentally. Based on the principle of least action [13, 14], micro-vibration equation of rock was introduced, in which the impacting frequency, impacting force, natural frequency of rock and mass of rock were considered. Researchers in Aberdeen University conducted a lot of experiments on RED and showed that the penetration rate was ten times as high as that by traditional drilling methods. Batako et al. [15] discussed the model of vibroimpacting penetration of self-exciting percussive-rotary drill bit. Results of the preliminary drilling experiment with superimposed dynamic action showed an improvement in the rate of penetration. Aspects of static force, amplitude and frequency were considered in Refs. [16, 17]. by Ekaterina Pavlovskaia and his co-authors, and two selected models of vibro-impacting drilling system were also compared in these papers. In recent years, a series of patents [18-21] on resonance enhanced rotary drilling have been applied to further ensure the feasibility of the technology.

Despite these technological advances, significant scientific interest and activities in this area, there are still a number of challenges to be addressed for the technology to become the norm in the industry. The change mechanism of energy response of rock under harmonic vibro-impacting is one of the problems that needs to be solved, which is also an indispensable part of rock-breaking mechanism of harmonic vibro-impacting drilling technology. This study focuses on the modeling of energy response of rock under harmonic vibro-impacting and the energy dissipation equations are given. Meanwhile, the results of numerical calculation are presented and the effects of natural frequency of rock, impacting frequency, impacting force and other parameters on energy response, are analyzed. Furthermore, the practical case has been proposed to illustrate the rock-breaking effect of harmonic vibro-impacting.

\section{Modeling of Energy Response of Rock}

\section{Physical Model}

Assuming that the rock is isotropic and homogeneous, the influence of pressure and temperature on the rock could be neglected, and the bit is simplified as a flat indenter. A micro-vibration model of rock is proposed, where the flat indenter is simulated as multiple springs, as shown in Fig. 1.

We divide the area under the indenter infinitely and select one of the infinitesimal elements to analyze, as shown in Fig. 2. The interaction between the spring and the rock element is simulated as follows: the rock element

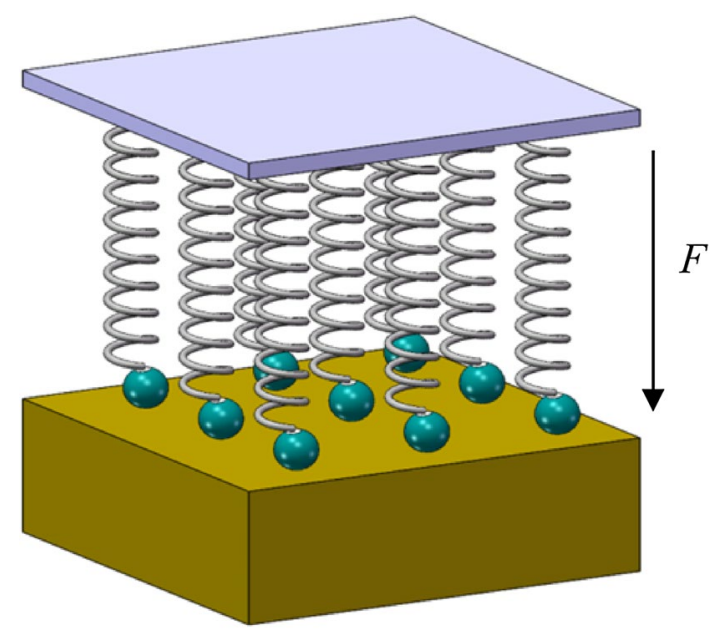

Fig. 1 The model of rock vibration

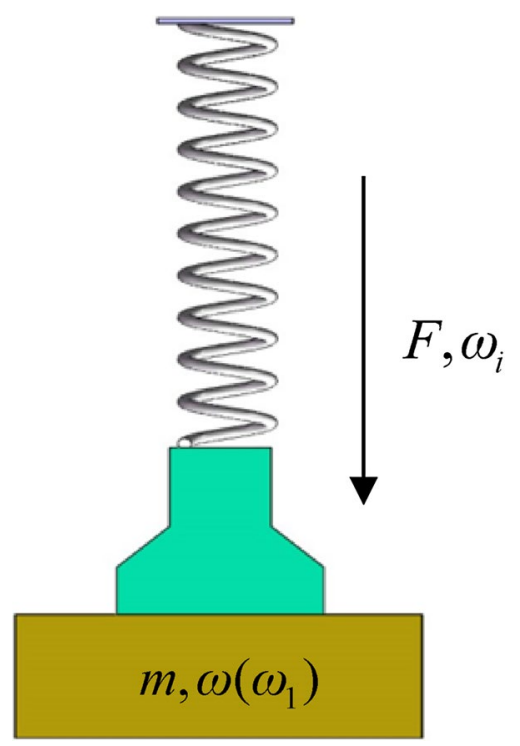

Fig. 2 The interaction between a spring and an infinitesimal element of rock 
has a mass of $m$ and a natural frequency of $\omega\left(\omega_{1}\right)$, and the spring exerts an excitation force $F$ with an excitation frequency $\omega_{i}$ on the rock element. Here, the stress under the flat indenter is assumed evenly distributed, and there is no coupling effect among the springs. Therefore, the interaction between the flat indenter and the rock can be simulated by the interaction between a spring and an infinitesimal element of rock.

\section{Mathematical Model}

The rock system under harmonic vibro-impacting can be divided into two kinds depending on damping of rock, which are the ideal system without damping and the actual system with damping.

\section{Energy Response Equation of Rock Without Damping}

In previous researches [13, 14], vibration response of rock under harmonic vibro-impacting without damping is given by

$x=a \cos (\omega t+\alpha)+b \cos \left(\omega_{i} t+\beta\right)$,

where $b=\frac{f}{m\left(\omega^{2}-\omega_{i}^{2}\right)}$.

Based on the least action principle, Lagrange function can be written as

$L=L(q, \dot{q}, t)=T-U=T-\left(U_{1}+U_{2}\right)$,

where $T$ is the kinetic energy, $U_{1}$ is the potential energy and $U_{2}$ is the external potential energy.

For one-dimensional vibration model under harmonic vibro-impacting, $L$ can be obtained from the above equation

$L=T-U_{1}-U_{2}=\frac{1}{2} m \dot{x}^{2}-\frac{1}{2} k x^{2}-\int F \mathrm{~d} x$.

As,

$p=\frac{\partial L}{\partial \dot{q}}=\frac{\partial L}{\partial \dot{x}}=m \dot{x}$.

Therefore, Hamiltonian energy equation is shown as

$$
\begin{aligned}
H= & p \dot{q}-L=m \dot{x} \cdot \dot{x}-\frac{1}{2} m \dot{x}^{2}+\frac{1}{2} k x^{2} \\
& +\int F \mathrm{~d} x=\frac{1}{2} m \dot{x}^{2}+\frac{1}{2} k x^{2}+\int F \mathrm{~d} x .
\end{aligned}
$$

Extending $U_{2}$ into a Taylor series and omitting the infinitesimals of second order, the resulting equation is given as

$U_{2}=U_{2}(0,0)+\frac{\partial U_{2}}{\partial x} \cdot x=F x+A$,

where $A$ is a constant and $U_{2}(0,0)$ could be eliminated if the zero potential energy surface is selected appropriately.
Because the rock is in the state of micro-vibration, extra potential energy can be simplified as

$\int F \mathrm{~d} x \approx F x=f a \cos (\omega t+\alpha) \cos \left(\omega_{i} t+\beta\right)+f b \cos ^{2}\left(\omega_{i} t+\beta\right)$.

Moreover, the following relations could also be obtained

$\begin{aligned} \frac{1}{2} m \dot{x}^{2}= & \frac{1}{2} m\left[a^{2} \omega^{2} \sin ^{2}(\omega t+\alpha)+b^{2} \omega_{i}^{2} \sin ^{2}\left(\omega_{i} t+\beta\right)\right. \\ & \left.+2 a b \omega \omega_{i} \sin (\omega t+\alpha) \sin \left(\omega_{i} t+\beta\right)\right],\end{aligned}$

$\frac{1}{2} k x^{2}=\frac{1}{2} k\left[a^{2} \cos ^{2}(\omega t+\alpha)+b^{2} \cos ^{2}\left(\omega_{i} t+\beta\right)\right.$ $\left.+2 a b \cos (\omega t+\alpha) \cos \left(\omega_{i} t+\beta\right)\right]$.

Take Eqs. (7)-(9) into Eq. (5), energy response equation of rock without damping is given by

$$
\begin{aligned}
H= & \frac{1}{2} m\left[a^{2} \omega^{2} \sin ^{2}(\omega t+\alpha)+b^{2} \omega_{i}^{2} \sin ^{2}\left(\omega_{i} t+\beta\right)\right. \\
& \left.+2 a b \omega \omega_{i} \sin (\omega t+\alpha) \sin \left(\omega_{i} t+\beta\right)\right] \\
& +\frac{1}{2} k\left[a^{2} \cos ^{2}(\omega t+\alpha)+b^{2} \cos ^{2}\left(\omega_{i} t+\beta\right)\right. \\
& \left.+2 a b \cos (\omega t+\alpha) \cos \left(\omega_{i} t+\beta\right)\right] \\
& +f a \cos (\omega t+\alpha) \cos \left(\omega_{i} t+\beta\right)+f b \cos ^{2}\left(\omega_{i} t+\beta\right) .
\end{aligned}
$$

Here, the energy dissipation of rock is caused by damping and impacting force. For the rock without damping, its energy dissipation is mainly due to the impacting force. When the direction of impacting force is opposite to the direction of rock vibration, energy dissipation would happen. Therefore, the energy dissipation of rock without damping is equal to the external potential energy $U_{2}$, namely Eq. (7).

\section{Energy Response Equation of Rock with Damping}

The vibration equation of rock with damping is given as

$m \ddot{x}+c \dot{x}+k x=F(t)$.

As the applied force is harmonic, it can be defined as follows:

$F=f \cos \left(\omega_{i} t+\beta\right)$.

Substitute Eq. (12) into Eq. (11), and its general solution is obtained

$x=a \mathrm{e}^{-\lambda t} \cos \left(\omega_{1} t+\alpha\right)+b_{1} \cos \left(\omega_{i} t+\beta+\delta\right)$,

where $\lambda=\frac{c}{2 m}, b_{1}=\frac{f}{m \sqrt{\left(\omega^{2}-\omega_{i}^{2}\right)^{2}+4 \lambda^{2} \omega_{i}^{2}}}, \omega_{1}=\sqrt{\omega^{2}-\lambda^{2}}$ and $\tan \delta=\frac{2 \lambda \omega_{i}}{\omega_{i}^{2}-\lambda^{2}}$.

Here, Eq. (13) is the vibration response of rock under harmonic vibro-impacting with damping. Based on the Eq. (13), the kinetic energy $T$, potential energy $U_{1}$ and extra potential energy $U_{2}$ can be described by 


$$
\begin{aligned}
\frac{1}{2} m \dot{x}^{2}= & \frac{1}{2} m\left[a^{2} \lambda^{2} \mathrm{e}^{-2 \lambda t} \cos ^{2}\left(\omega_{1} t+\alpha\right)+a^{2} \omega_{1}^{2} \mathrm{e}^{-2 \lambda t}\right. \\
& \sin ^{2}\left(\omega_{1} t+\alpha\right)+b_{1}^{2} \omega_{i}^{2} \sin ^{2}\left(\omega_{i} t+\beta+\delta\right) \\
& +2 a^{2} \lambda \omega_{1} \mathrm{e}^{-2 \lambda t} \cos \left(\omega_{1} t+\alpha\right) \sin \left(\omega_{1} t+\alpha\right) \\
& +2 a b_{1} \lambda \omega_{i} \mathrm{e}^{-\lambda t}\left(\omega_{1} t+\alpha\right) \sin \left(\omega_{i} t+\beta+\delta\right) \\
& \left.+2 a b_{1} \omega_{1} \omega_{i} \mathrm{e}^{-\lambda t} \sin \left(\omega_{1} t+\alpha\right) \sin \left(\omega_{i} t+\beta+\delta\right)\right],
\end{aligned}
$$$$
\frac{1}{2} k x^{2}=\frac{1}{2} k\left[a^{2} \mathrm{e}^{-2 \lambda t} \cos ^{2}\left(\omega_{1} t+\alpha\right)+b_{1}^{2} \cos ^{2}\left(\omega_{i} t+\beta+\delta\right)\right.
$$$$
\left.+2 a b_{1} \mathrm{e}^{-\lambda t} \cos \left(\omega_{1} t+\alpha\right) \cos \left(\omega_{i} t+\beta+\delta\right)\right]
$$

$$
\begin{aligned}
\int F \mathrm{~d} x \approx F x= & a f \mathrm{e}^{-\lambda t} \cos \left(\omega_{1} t+\alpha\right) \cos \left(\omega_{i} t+\beta\right) \\
& +b_{1} f \cos \left(\omega_{i} t+\beta+\delta\right) \cos \left(\omega_{i} t+\beta\right) .
\end{aligned}
$$

Take Eqs. (14)-(16) into Eq. (5), then the equation of energy response is given by

$$
\begin{aligned}
H= & \frac{1}{2} m\left[a^{2} \lambda^{2} \mathrm{e}^{-2 \lambda t} \cos ^{2}\left(\omega_{1} t+\alpha\right)+a^{2} \omega_{1}^{2} \mathrm{e}^{-2 \lambda t}\right. \\
& \sin ^{2}\left(\omega_{1} t+\alpha\right)+b_{1}^{2} \omega_{i}^{2} \sin ^{2}(v) \\
& +2 a^{2} \lambda \omega_{1} \mathrm{e}^{-2 \lambda t} \cos \left(\omega_{1} t+\alpha\right) \sin \left(\omega_{1} t+\alpha\right) \\
& +2 a b_{1} \lambda \omega_{i} \mathrm{e}^{-\lambda t} \cos \left(\omega_{1} t+\alpha\right) \sin \left(\omega_{i} t+\beta+\delta\right) \\
& \left.+2 a b_{1} \omega_{1} \omega_{i} \mathrm{e}^{-\lambda t} \sin \left(\omega_{1} t+\alpha\right) \sin \left(\omega_{i} t+\beta+\delta\right)\right] \\
& +\frac{1}{2} k\left[a^{2} \mathrm{e}^{-2 \lambda t} \cos ^{2}\left(\omega_{1} t+\alpha\right)+b_{1}^{2} \cos ^{2}\left(\omega_{i} t+\beta+\delta\right)\right. \\
& \left.+2 a b_{1} \mathrm{e}^{-\lambda t} \cos \left(\omega_{1} t+\alpha\right) \cos \left(\omega_{i} t+\beta+\delta\right)\right] \\
& +a f \mathrm{e}^{-\lambda t} \cos \left(\omega_{1} t+\alpha\right) \cos \left(\omega_{i} t+\beta\right) \\
& +f b_{1} \cos \left(\omega_{i} t+\beta+\delta\right) \cos \left(\omega_{i} t+\beta\right) .
\end{aligned}
$$

Equation (17) is the energy response equation of rock with damping.

To show the convergence of the solution, a specific case is given below. For $a=1, b=1, c=0.05, k=1, m=10$, $f=1000, \omega_{1}=500, \omega_{i}=500, \alpha=0, \beta=0, \delta=0$, the solution can be written as

$$
\begin{aligned}
H= & \left(3,750,000 \mathrm{e}^{-0.1 t}+1,250,000\right) \sin ^{2}(500 t)+\left(0.5125 \mathrm{e}^{-0.1 t}\right. \\
& \left.+1001 \mathrm{e}^{-0.05 t}+1000.5\right) \cos ^{2}(500 t)+500 \mathrm{e}^{-0.1 t} \\
& \sin (500 t) \cos (500 t) .
\end{aligned}
$$

Here, the energy dissipation of rock is caused by both damping and impacting force. Because the rock is in the state of micro-vibration, the energy dissipation caused by damping can be derived as follows.

Take the derivative of $x$, the vibration velocity of the rock is obtained by

$$
\begin{aligned}
& \dot{x}=-a \lambda \mathrm{e}^{-\lambda t} \cos \left(\omega_{1} t+\alpha\right)-a \omega_{1} \mathrm{e}^{-\lambda t} \sin \left(\omega_{1} t+\alpha\right) \\
& \quad-b_{1} \omega_{i} \sin \left(\omega_{i} t+\beta+\delta\right), \\
& \int c \dot{x} \mathrm{~d} x \approx c \dot{x} \cdot x=-a^{2} c \lambda \mathrm{e}^{-2 \lambda t} \cos ^{2}\left(\omega_{1} t+\alpha\right) \\
& -a^{2} c \omega_{1} \mathrm{e}^{-2 \lambda t} \sin \left(\omega_{1} t+\alpha\right) \cos \left(\omega_{1} t+\alpha\right) \\
& -a b_{1} c \omega_{i} \mathrm{e}^{-\lambda t} \sin \left(\omega_{i} t+\beta+\delta\right) \cos \left(\omega_{1} t+\alpha\right) \\
& -a b_{1} c \lambda \mathrm{e}^{-\lambda t} \cos \left(\omega_{i} t+\alpha\right) \cos \left(\omega_{i} t+\beta+\delta\right) \\
& -a b_{1} c \omega_{i} \mathrm{e}^{-\lambda t} \sin \left(\omega_{1} t+\alpha\right) \cos \left(\omega_{i} t+\beta+\delta\right) \\
& -b_{1}^{2} \omega_{i} \sin \left(\omega_{i} t+\beta+\delta\right) \cos \left(\omega_{i} t+\beta+\delta\right)
\end{aligned}
$$

As the energy dissipation which is caused by impacting force is Eq. (16), the energy dissipation of rock with damping is given by

$$
\begin{aligned}
W= & \int c \dot{x} \mathrm{~d} x+\int F \mathrm{~d} x=-a^{2} c \lambda \mathrm{e}^{-2 \lambda t} \cos ^{2}\left(\omega_{1} t+\alpha\right) \\
& -a^{2} c \omega_{1} \mathrm{e}^{-2 \lambda t} \sin \left(\omega_{1} t+\alpha\right) \cos \left(\omega_{1} t+\alpha\right) \\
& -a b_{1} c \omega_{i} \mathrm{e}^{-\lambda t} \sin \left(\omega_{i} t+\beta+\delta\right) \cos \left(\omega_{1} t+\alpha\right) \\
& -a b_{1} c \lambda \mathrm{e}^{-\lambda t} \cos \left(\omega_{i} t+\alpha\right) \cos \left(\omega_{i} t+\beta+\delta\right) \\
& -a b_{1} c \omega_{i} \mathrm{e}^{-\lambda t} \sin \left(\omega_{1} t+\alpha\right) \cos \left(\omega_{i} t+\beta+\delta\right) \\
& -b_{1}^{2} \omega_{i} \sin \left(\omega_{i} t+\beta+\delta\right) \cos \left(\omega_{i} t+\beta+\delta\right) \\
& +a f \mathrm{e}^{-\lambda t} \cos \left(\omega_{1} t+\alpha\right) \cos \left(\omega_{i} t+\beta\right) \\
& +b_{1} f \cos \left(\omega_{i} t+\beta+\delta\right) \cos \left(\omega_{i} t+\beta\right) .
\end{aligned}
$$

\section{Results and Discussion}

The models of energy response of rock are solved by MATLAB, and the influences of natural frequency of rock, impacting frequency and force, damping and other factors on energy response, are analyzed. The basic calculation parameters are shown in Table 1.
Table 1 The basic calculation parameters of energy response model

\begin{tabular}{llllllll}
\hline$A$ & $B$ & $M$ & $K$ & $C$ & $F$ & $\omega_{1}$ & $\omega_{i}$ \\
\hline 0.001 & 0.001 & 30 & 1 & 0.5 & 1000 & 400 & 400 \\
& & 60 & 2 & 1 & 2000 & 500 & 500 \\
& 100 & 3 & 1.5 & 3000 & 600 & 600 \\
\hline
\end{tabular}



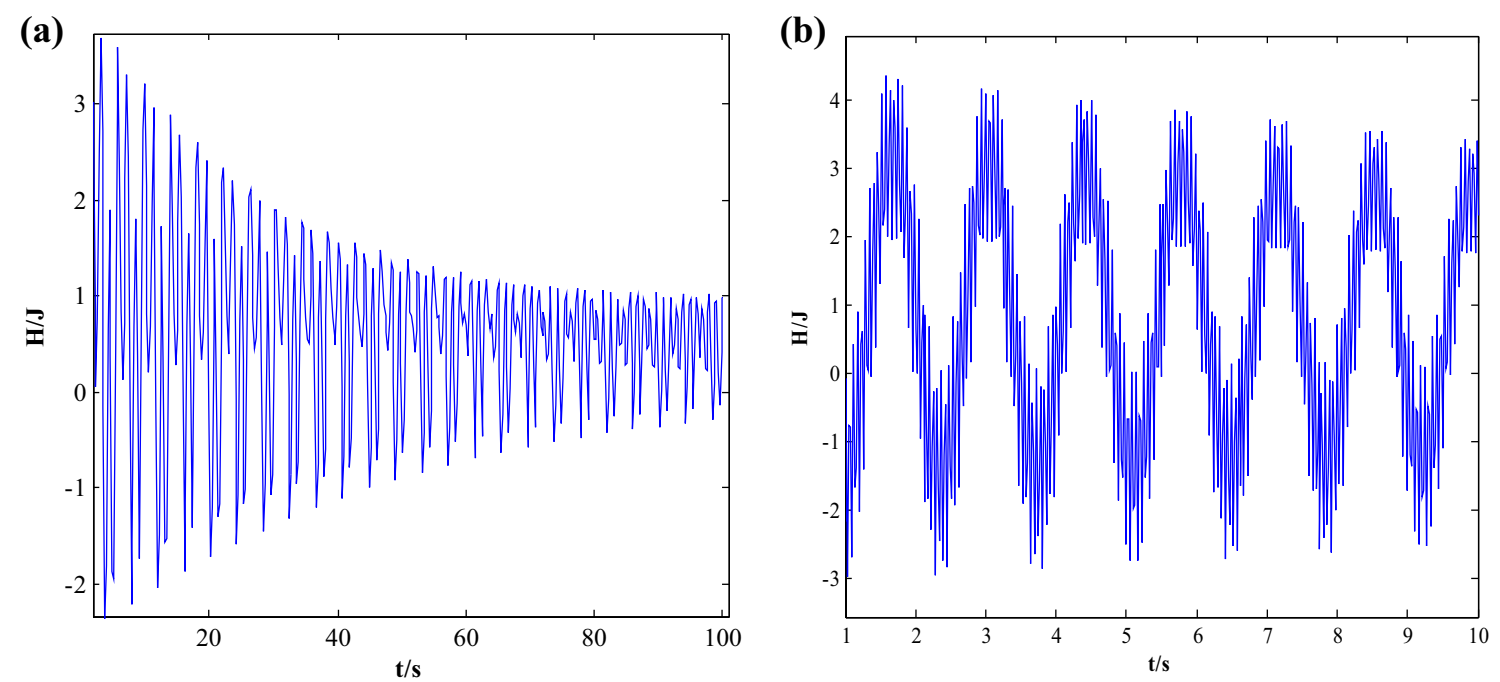

Fig. 3 The variation of energy response of rock with damping over time. a Time interval of 0-100 s. b Time interval of 0-10 s
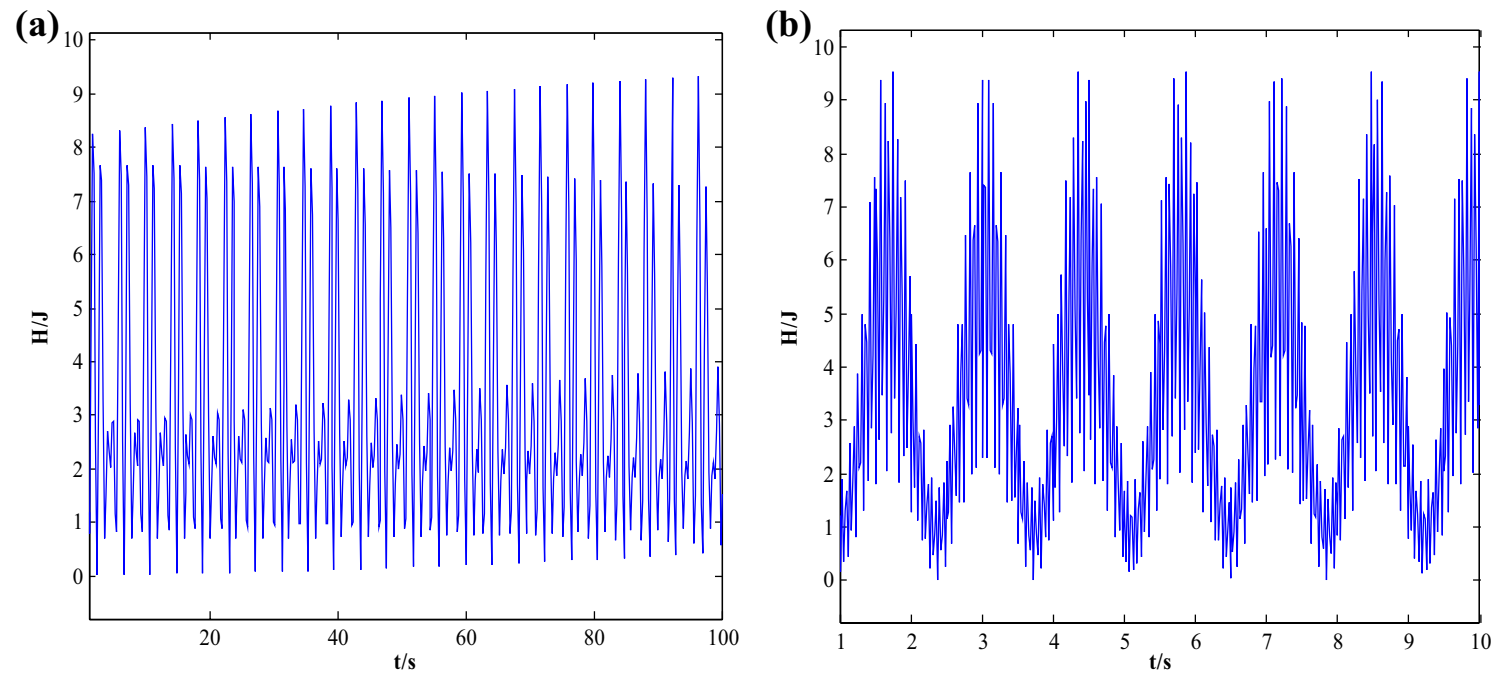

Fig. 4 The variation of energy response of rock without damping over time. a Time interval of 0-100 s. b Time interval of 0-10 s

\section{Variation of Energy Response}

Figures 3 and 4 demonstrate the variation of energy response of rock with and without damping over time under harmonic vibro-impacting, respectively. By comparing Fig. 3 with Fig. 4, it can be concluded that the energy response of rock with damping decays regularly over time in the form of harmonic vibration under harmonic vibro-impacting, and increases regularly instead for the rock without damping. Our calculation proves that the damping consumes the system energy of rock. In addition, because the impacting force does positive work or negative work depending on whether it is in the same direction with rock vibration, the energy response of rock is in a state of dynamic balance. As a result, it presents harmonic vibration form.

Based on the analysis above, it can be seen that the existence of damping only affects the variation of energy response of rock and does not have an impact on vibration mode. Therefore, the model of energy response of rock with damping will be given as an example in the following content.

\section{Influence of Natural Frequency of Rock}

The natural frequency of the rock is considered first. It is intuitive that the natural frequency of rock will have a strong influence on energy response. Here, the response 

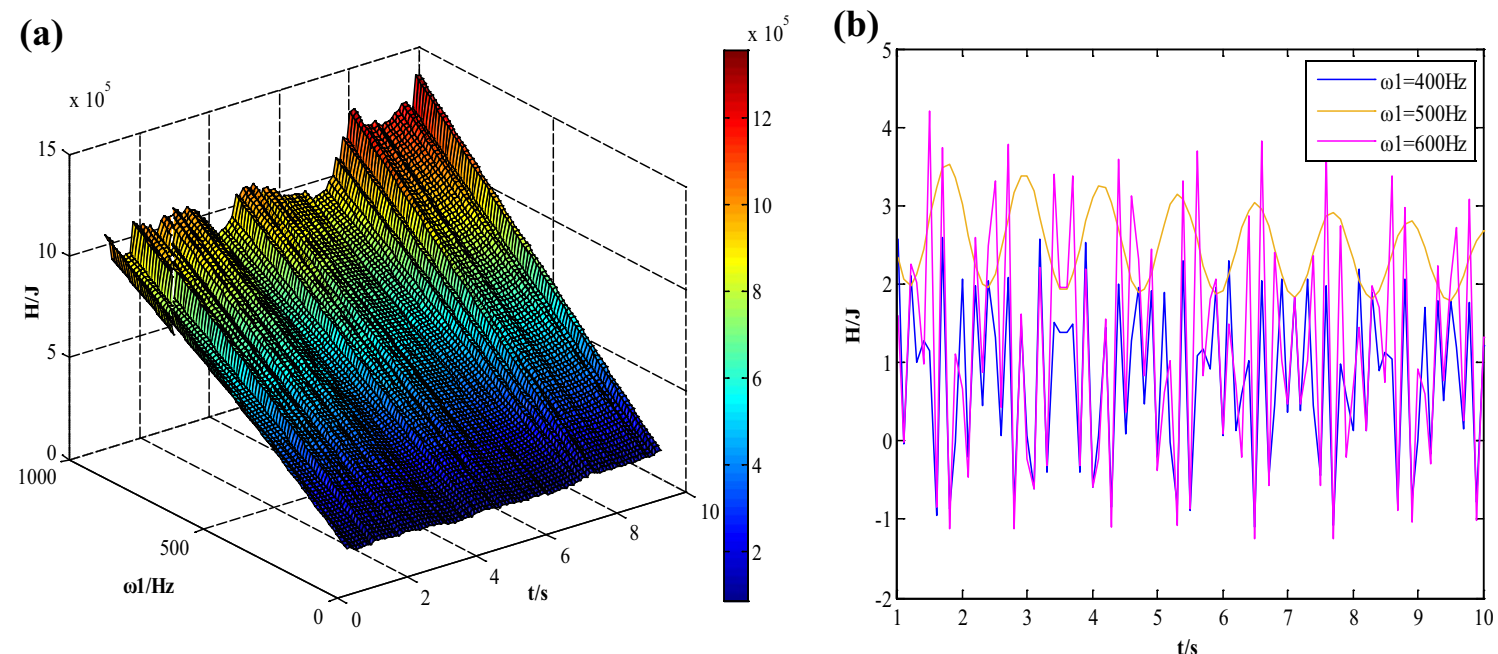

Fig. 5 Effect of natural frequency of rock on energy response

energy is calculated for impacting frequency of $500 \mathrm{~Hz}$, impacting force of $1000 \mathrm{~N}$ and damping coefficient of 0.5 . Figure 5a shows the three-dimensional variation diagram of energy response of rock. It shows that the response energy presents a trend of increase with the increasing natural frequency of rock and fluctuates more violently at the same time. This is for the reason that the natural frequency of rock exists in the sine or cosine function of energy response equation, so that it determines the vibration period of energy response.

The two-dimensional variation diagram of energy response is presented in Fig. 5b. It illustrates that the peak of energy response increases with the increasing natural frequency of rock under the same impacting frequency. When the impacting frequency and the natural frequency of rock are equal, energy response is in the most stable state of harmonic vibration. In this case, impacting force keeps the same pace with rock vibration so that it does not interfere with the energy response.

\section{Influence of Impacting Frequency}

The impacting frequency is another major parameter that could influence the energy response. The variation diagram of energy response calculated for natural frequency of rock of $500 \mathrm{~Hz}$, impacting force of $1000 \mathrm{~N}$ and damping coefficient of 0.5 is presented in Fig. 6, where Fig. 6a, b shows three-dimensional and two-dimensional variation diagrams of energy response, respectively. It is obvious that response energy increases with the increasing impacting frequency.
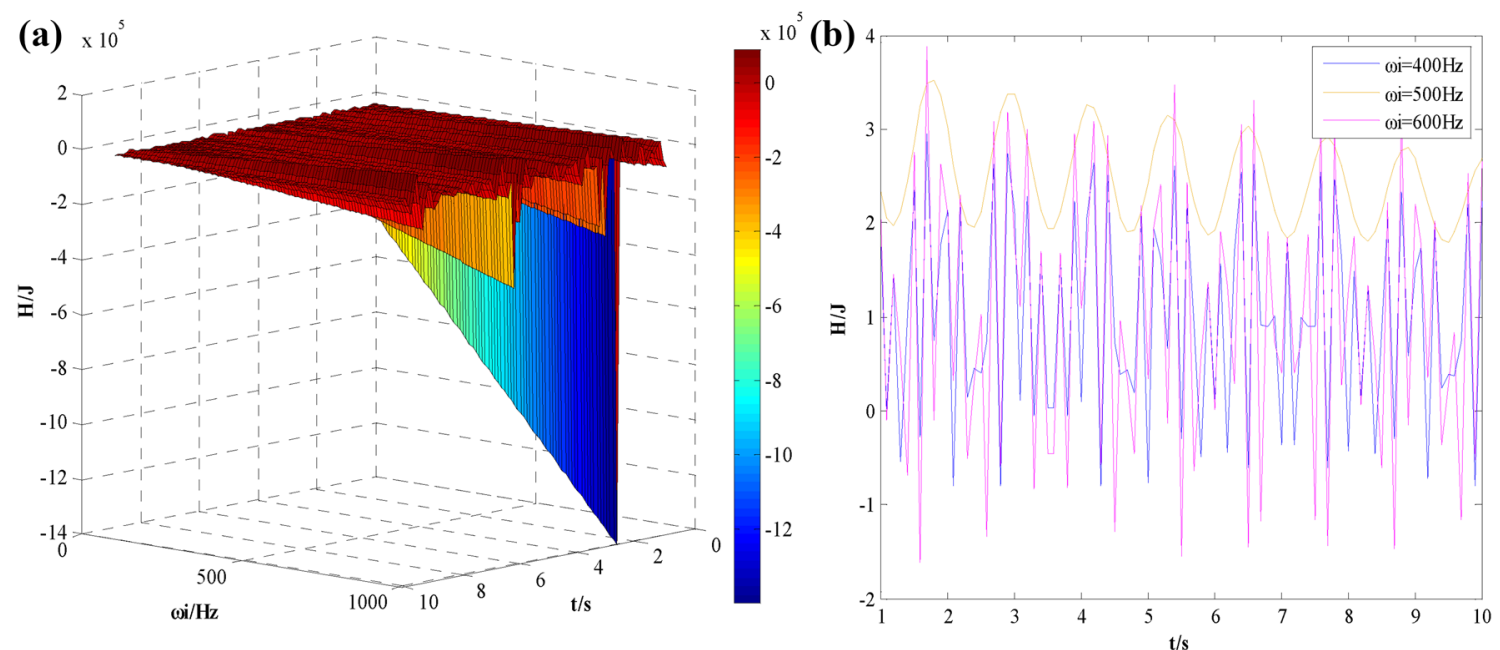

Fig. 6 Effect of impacting frequency on energy response 
What is more, the response energy is in the state of stable harmonic vibration when the rock resonates. The reason for this phenomenon is the same as the natural frequency of rock.

\section{Influence of Impacting Force}

To estimate the effect of impacting force on energy response, the model with damping is simulated for varying impacting forces and the results are shown in Fig. 7. As can be seen from Fig. 7a, impacting force affects the response energy significantly. With the increasing impacting force, the response energy increases linearly at the same time. Two-dimensional variation diagram of energy response is shown in Fig. 7b. It reveals that the overall response energy increases with the increasing impacting force. Furthermore, we can observe that response energy is in the law of stable harmonic vibration both in Fig. 7a, b. Besides, it can be seen from the energy response equation of rock, impacting force is as the coefficient of sine or cosine function in the equation, so it plays a decisive role on the amplitude of energy response.

\section{Influence of Damping Coefficient}

Damping coefficient is also an important factor governing the energy response of rock. The variation of energy response over time in different damping coefficients is shown in Fig. 8. Here, Fig. 8a, b corresponds to different levels of damping coefficient, impacting frequency of $500 \mathrm{~Hz}$, natural frequency of rock of $500 \mathrm{~Hz}$ and impacting force of $1000 \mathrm{~N}$ and all other parameters are specified in the figure.

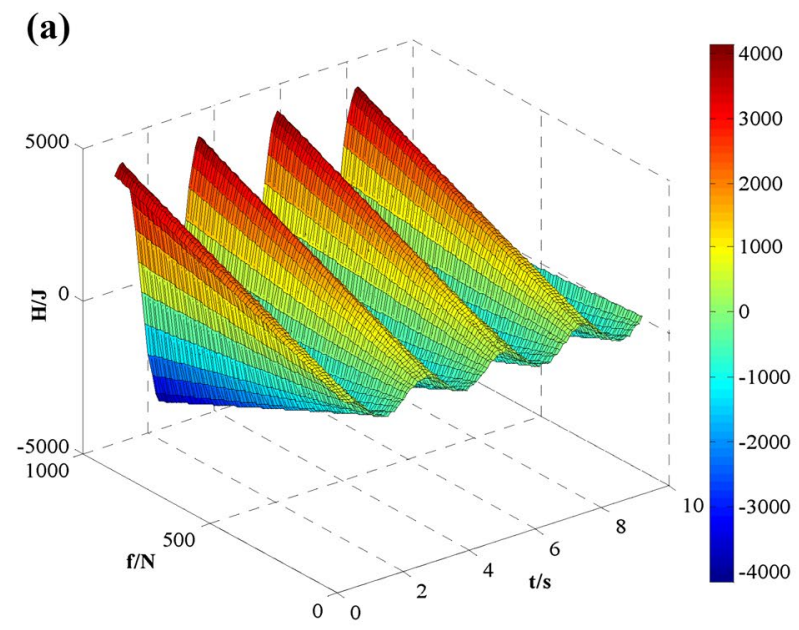

(b)

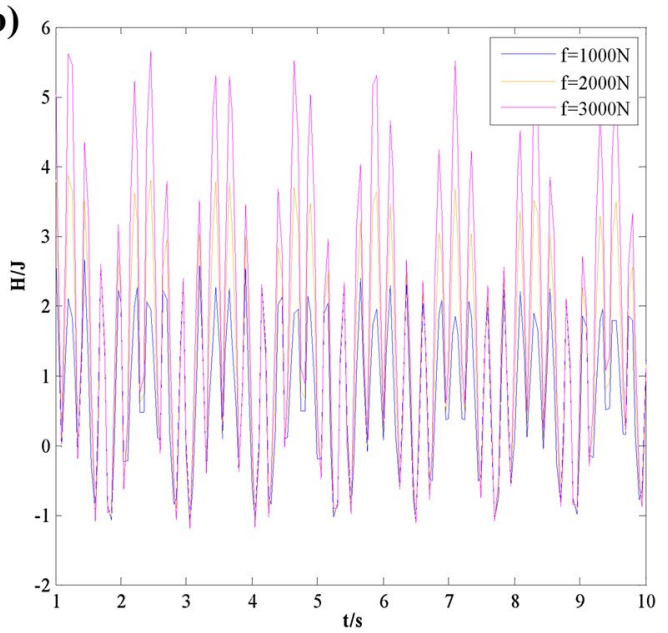

Fig. 7 Effect of impacting force on energy response

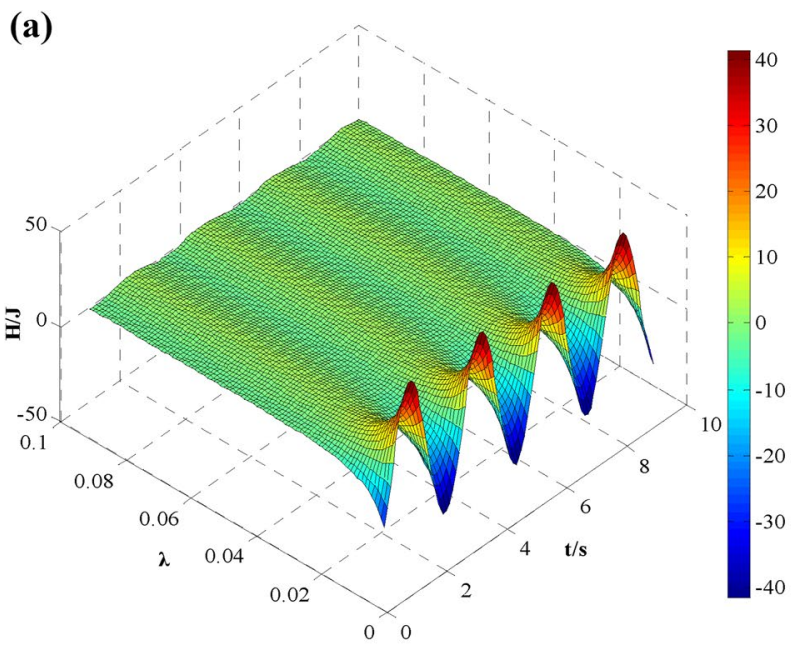

(b)

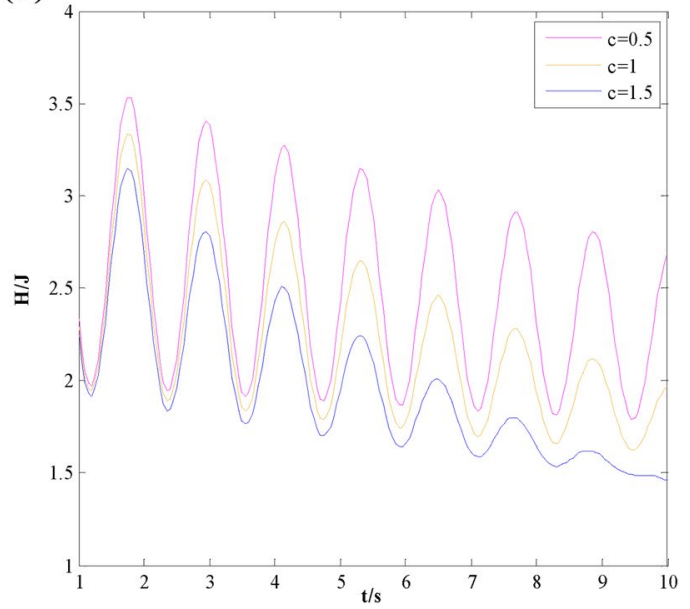

Fig. 8 Effect of damping coefficient on energy response 
Because $\lambda=c / 2 m, \lambda$ increases linearly with the increasing damping coefficient. As can be seen from Fig. 8a, when the rock system transits from under-damped phase to damping phase, response energy changes in the form of regular harmonic vibration. However, when the rock system transits from damping phase to over-damped phase, response energy becomes zero and does not have any fluctuation. This is because when the rock system is in the state of over-damped, even harmonic vibro-impacting cannot cause the vibration of rock. As a result, the response energy is not changed. Figure $8 \mathrm{~b}$ shows that the maximum amplitude of response energy reduces with the increasing damping coefficient, and response energy decays faster. What has been discussed above is the fact that damping coefficient has effect on amplitude of response energy which is similar to the impacting force.

\section{Influence of Stiffness of Rock}

Figure 9 demonstrates the dependence of response energy on time for three different values of the stiffness of rock, which is calculated for impacting frequency of $500 \mathrm{~Hz}$, natural frequency of rock of $500 \mathrm{~Hz}$ and impacting force of $1000 \mathrm{~N}$. It is surprising to note that response energy keeps the same form of harmonic vibration with the increasing rock stiffness. Based on the energy response equation, we can see that the proportion of rock stiffness item in equation is very small compared with the mass and impacting force item, so that it can be neglected. This is why the rock stiffness does not have an impact on the response energy.

\section{Influence of Mass of Rock}

The variation of energy response in different masses of rock described above is calculated for values impacting frequency of $500 \mathrm{~Hz}$, natural frequency of rock of $500 \mathrm{~Hz}$ and impacting force of $1000 \mathrm{~N}$ as shown in Fig. 10. Similar to the influence law of impacting force on the response energy, the variation is also in the law of stable harmonic vibration. In addition, response energy increases linearly with the increasing impacting force at the same time. The reason for this phenomenon is the same as the impacting force and damping coefficient.

In conclusion, it is important to note that if natural frequency of rock or impacting frequency changes, the harmonic vibration of energy response of rock will be unstable. However, if impacting force, damping coefficient or mass of rock changes, the harmonic vibration of energy response of rock will be stable and regular. These indicate that natural frequency of rock and impacting frequency will have effect on the vibration period of the energy response, while impacting force, damping coefficient and mass of rock will play a decisive role on the vibration amplitude of the energy response. The above conclusions can provide reference for adjusting vibration parameters in drilling operation.

\section{Practical Cases}

To achieve the application of harmonic vibro-impacting drilling technology in the field operation, high-frequency and low-amplitude axial impacting tool is developed by Northeast Petroleum University. It can convert drilling fluid energy into high-frequency harmonic vibration impacting to drill bit through its unique flow path inside. The tool's impacting frequency is of $15 \mathrm{~Hz}$, bit pressure is of 6-14 t, rotating speed is of the 50-60 rpm and the flowing capacity is of $28-32 \mathrm{~L} / \mathrm{min}$. The physical picture of high-frequency and low-amplitude axial impacting tool is shown in Fig. 11.
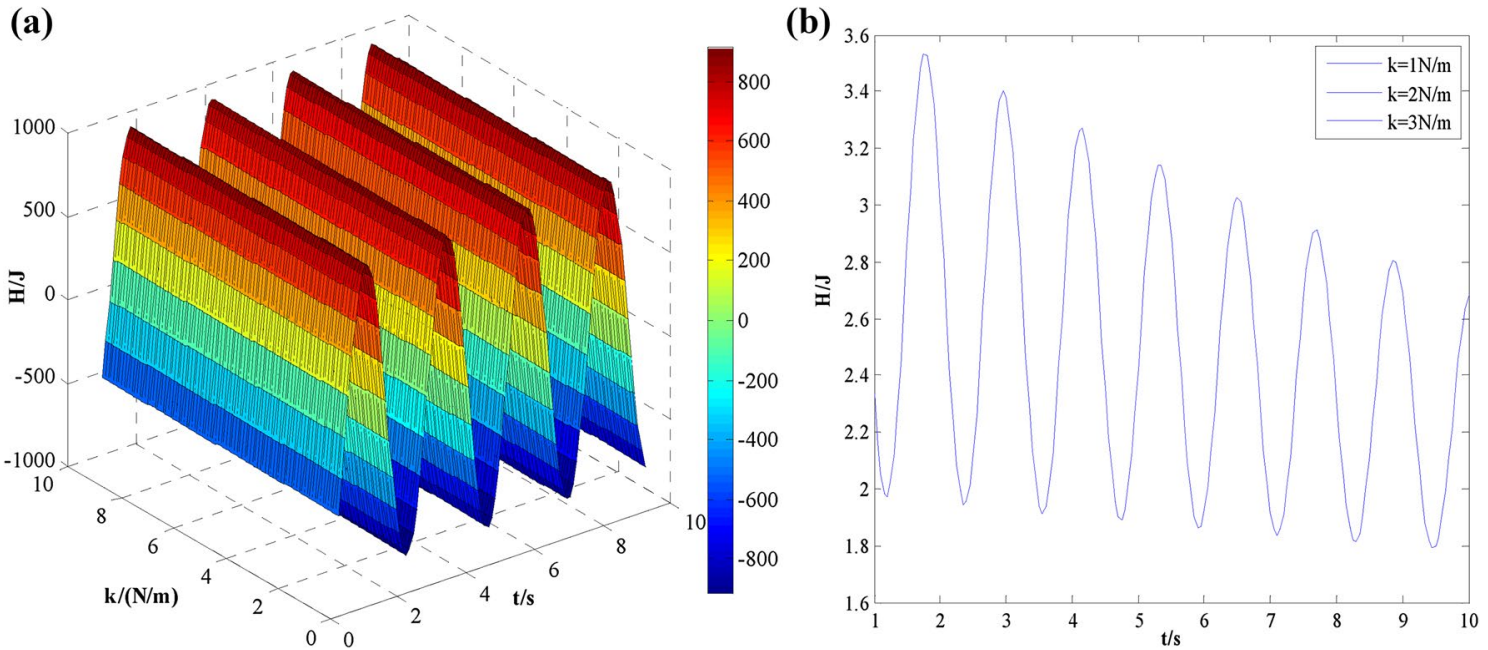

Fig. 9 Effect of stiffness of rock on energy response

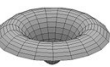



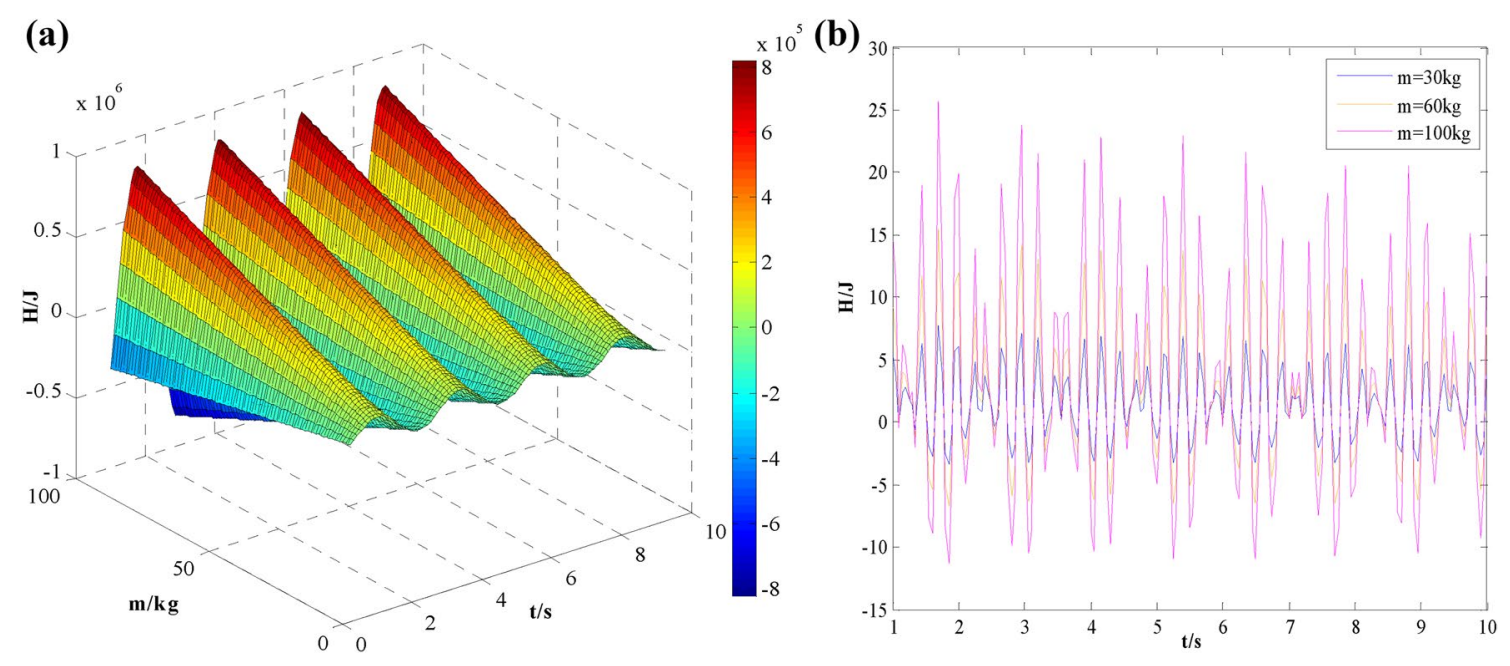

Fig. 10 Effect of mass of rock on energy response

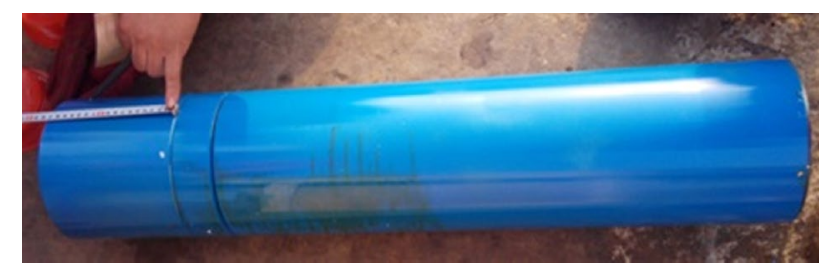

Fig. 11 High-frequency and low-amplitude axial impacting tool

The impacting tool is applied to $M$ well of $6500-6700 \mathrm{~m}$ whose lithology mainly includes fine grain sandstone, brown mudstone and silty mudstone. Because the impacting frequency of tool is less than the natural frequency of drilled rock, harmonic vibro-impacting mainly plays a role in rock breaking instead of resonance. The drilling rate curves are given below.
As shown in Fig. 12, the average penetration rate of conventional drilling tool is $1.88 \mathrm{~m} / \mathrm{h}$ and that is $3.33 \mathrm{~m} / \mathrm{h}$ by impacting tool in the depth of 6574-6668 $\mathrm{m}$, which is increased by $77.1 \%$. Similarly, the average penetration rate of conventional drilling tool is $1.84 \mathrm{~m} / \mathrm{h}$ and that is $2.91 \mathrm{~m} / \mathrm{h}$ by impacting tool in the depth of $6500-6596 \mathrm{~m}$, which is increased by $58.2 \%$.

In a word, the development of high-frequency and lowamplitude axial impacting tool makes it possible for field applications of harmonic vibro-impacting drilling technology. From the field data, we can see that the penetration rate has been greatly improved using impacting tool. This is based on the fact that harmonic vibro-impacting can make the energy response of rock increase regularly and steadily and avoid bit bouncing, tooth breakage and other issues. Finally, it contributes significantly to the rock
Fig. 12 Variation of drilling rate of different tools

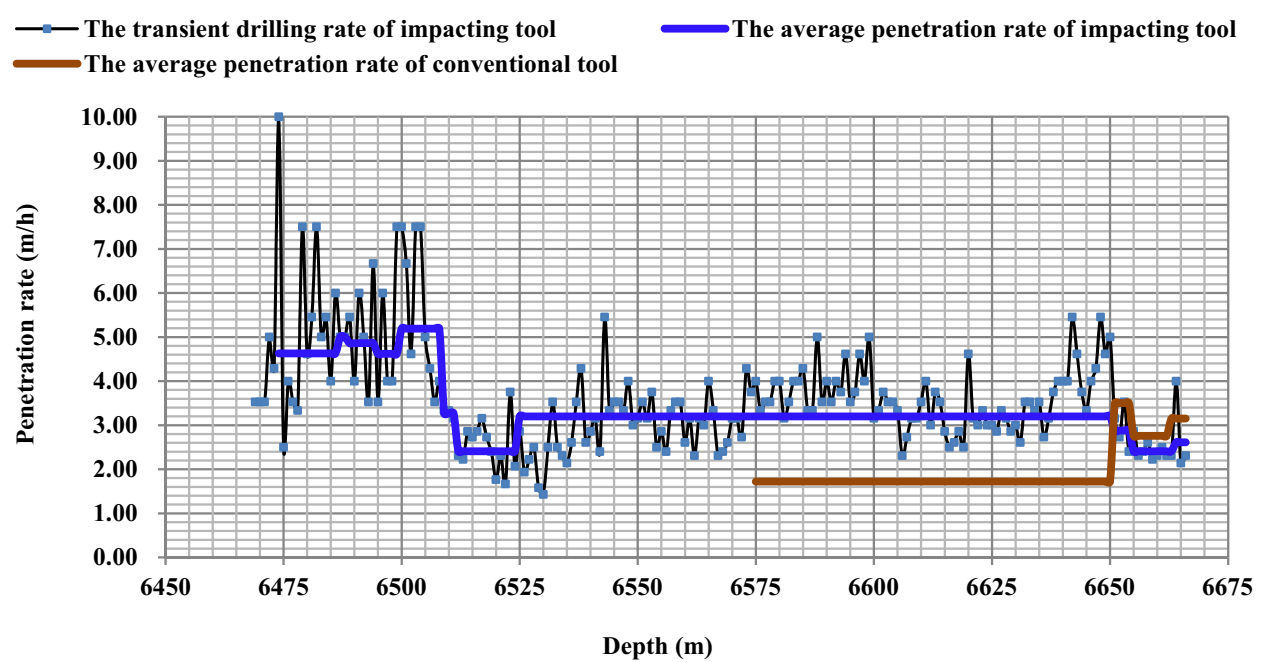


breaking and the purpose of improving the penetration rate is achieved.

\section{Conclusions}

Considering the undamped and damped condition, the energy response model of rock under harmonic vibroimpacting is presented. MATLAB is used to solve the model, and effects of natural frequency of rock, impacting frequency and force, damping coefficient, stiffness and mass of rock on energy response are also analyzed. In addition, energy dissipation equations of rock with and without damping are given.

Our investigations confirm that due to the damping of rock, response energy of rock decays regularly over time in the harmonic form under harmonic vibro-impacting. When the rock system transits from under-damped phase to damping phase, the energy response changes in the form of regular harmonic vibration. However, when the rock system transits from damping phase to over-damped phase, the energy response is zero and does not have any fluctuation.

The numerical calculations indicate that the response energy of rock increases with the increasing natural frequency and mass of rock, impacting frequency and force, and is not affected by stiffness of rock. It can also be concluded that natural frequency of rock and impacting frequency play a decisive role on the vibration period of energy response, while impacting force, damping coefficient and mass of rock decide the vibration amplitude of energy response.

Based on the analysis undertaken, the variation mechanism of energy response of rock under harmonic vibroimpacting has been found out and the rock-breaking effect of the technology has been verified. Harmonic vibro-impacting drilling technology, as a new technology, is of great significance to enrich drilling methods and promote the development of oil and gas well engineering. The study on the modeling of energy response of rock under harmonic vibroimpacting can provide a theoretical basis for applying harmonic vibro-impacting drilling technology.

Acknowledgements The support of National Natural Science Foundation of China (No. 51704074) and Youth Science Foundation of Heilongjiang Province (No. QC2018049) are gratefully acknowledged. The work is also supported by Talent Cultivation Foundation (No. SCXHB201703; No. ts26180119; No. td26180141) and Youth Science Foundation (No. 2019QNL-07) of Northeast Petroleum University.

Open Access This article is distributed under the terms of the Creative Commons Attribution 4.0 International License (http://creativeco mmons.org/licenses/by/4.0/), which permits unrestricted use, distribution, and reproduction in any medium, provided you give appropriate credit to the original author(s) and the source, provide a link to the Creative Commons license, and indicate if changes were made.

\section{References}

1. Chang DY, Li GS, Shen ZH et al (2011) The stress field of bottom hole in deep and ultra-deep wells. Acta Pet Sin 32:697-703

2. Cai C, Wu KS, Lian D et al (2015) Study of rock-breaking mechanism under single-tooth impact. Rock Soil Mech 36:1659-1675

3. Zhao J, Xu YJ, Xing XY et al (2014) A theoretical model and experiment of brittle rock impacted by particles. J China Univ Min Technol 43:1108-1112

4. Tang LP, Zhu XH, Shi CS (2017) Effects of high-frequency torsional impacts on mitigation of stick-slip vibration in drilling system. J Vib Eng Technol 5:111-122

5. Tang LP, Zhu XH, Shi CS et al (2016) Investigation of the damping effect on stick-slip vibration of oil and gas drilling system. J Vib Eng Technol 4:79-88

6. Cheng YX, Li GS, Wang HZ et al (2014) Phase control of wellbore fluid during supercritical $\mathrm{CO}_{2}$ jet fracturing. Acta Pet Sin 35:1182-1187

7. Li W, Yan T, Li SQ et al (2013) Rock fragmentation mechanisms and an experimental study of drilling tools during high-frequency harmonic vibration. Pet Sci 10:205-211

8. Liu H, Zhang WH, Zhu JH (2013) Structural topology optimization and frequency influence analysis under harmonic force excitations. Chin J Theor Appl Mech 45:588-597

9. Aguiar RR, Weber HI (2007) Development of a vibro impact device for the resonance hammer drilling. In: Proceedings of the XII international symposium on dynamic problems of mechanics

10. Ostasevicius V, Gaidys R, Rimkeviciene J et al (2010) An approach based on tool mode control for surface roughness reduction in high-frequency vibration cutting. J Sound Vib 329:4866-4879

11. Beltran-Carbajal F, Silva-Navarro G, Vazquez-Gonzalez B (2016) Multi-frequency harmonic vibration suppression on mass-springdamper systems using active vibration absorbers. J Vib Eng Technol 4:1-12

12. Li W, Yan T et al (2013) Rock response mechanism and rock breaking test analysis for impact of high frequency vibration drilling tool. Pet Drill Tech 41:25-28

13. Li SQ, Yan T, Wang XJ et al (2014) The micro vibration equation of rock and its analysis basing on the principle of least action. Pet Drill Tech 42:66-70

14. Li SQ, Yan T, Li W et al (2015) Modeling of vibration response of rock by harmonic impact. J Nat Gas Sci Eng 23:90-96

15. Batako AD, Babitsky VI, Halliwell NA (2004) Modelling of vibro-impact penetration of self-exciting percussive-rotary drill bit. J Sound Vib 271:209-225

16. Pavlovskaia E, David CH, Wiercigroch M (2013) Modelling of high frequency vibro-impact drilling. Int J Mech Sci. https://doi. org/10.1016/j.ijmecsi.2013.08.009

17. Wiercigroch M, Krivtsov AM, Wojewoda J (2008) Vibrational energy transfer via modulated impacts for percussive drilling. J Theor Appl Mech 46:715-726

18. Hall DR, Balley J, Kudla M et al (2009) Drilling at a resonant frequency. US Patent: 7,591,327 B2

19. Wiercigroch M (2010) Resonance enhanced drilling: method and apparatus. US Patent: 319,994

20. Wiercigroch M (2012) Resonance enhanced rotary drilling. US Patent: 0,241,219 A1

21. Wiercigroch $\mathrm{M}$ (2014) Resonance enhanced rotary drilling module. US Patent: 0,116,777 A1

Publisher's Note Springer Nature remains neutral with regard to jurisdictional claims in published maps and institutional affiliations. 